\title{
BMJ Open Retrospective study of the influence of hypothyroidism on liver function before radioiodine therapy in China: a comparison analysis based on patients with differentiated thyroid cancer
}

\author{
Yanhui Ji (D) , ${ }^{1}$ Wei Zheng, ${ }^{1}$ Zhaowei Meng, ${ }^{1}$ Cailan $\mathrm{Wu},{ }^{2}$ Jian Tan, ${ }^{1}$ Renfei Wang ${ }^{1}$
}

To cite: Ji Y, Zheng W, Meng Z, et al. Retrospective study of the influence of hypothyroidism on liver function before radioiodine therapy in China: a comparison analysis based on patients with differentiated thyroid cancer. BMJ Open 2022;12:e045562. doi:10.1136/ bmjopen-2020-045562

- Prepublication history for this paper is available online. To view these files, please visit the journal online (http://dx.doi. org/10.1136/bmjopen-2020045562).

Received 22 0ctober 2020 Accepted 22 December 2021

Check for updates

(C) Author(s) (or their employer(s)) 2022. Re-use permitted under CC BY-NC. No commercial re-use. See rights and permissions. Published by BMJ.

${ }^{1}$ Nuclear Medicine, Tianjin Medical University General Hospital, Tianjin, China

${ }^{2}$ Nuclear Medicine, Tianjin Fourth Central Hospital, Tianjin, China

Correspondence to Dr Renfei Wang: roslyn_en@163.com

\section{ABSTRACT}

Purpose The aim of the present study is to investigate the risk factors for hepatic dysfunction before radioiodine therapy in patients with differentiated thyroid cancer (DTC). Methods 996 patients (314 men, 682 women; age of $45.07 \pm 12.98$ years) with postoperative DTC were recruited and divided into two groups including patients with and without hepatic dysfunction. The changes in baseline data and traced liver function levels, together with other metabolic profiles, were compared between the two groups. Result Overall, $31.6 \%$ of patients had hepatic dysfunction. Higher aspartate aminotransferase and/or alanine aminotransferase was the most common abnormality (the prevalence rate was $47.5 \%$ ). The percentages of mild and moderate hepatic dysfunction were $80.0 \%$ and $20.0 \%$, respectively. Univariate analyses demonstrated that the most prominent risk factors for hepatic dysfunction $(0 R=0.324-3.171, p<0.01)$ were male sex with levothyroxine discontinuation and free triiodothyronine $<2.01 \mathrm{pmol} / \mathrm{L}$, free thyroxine $\left(\mathrm{FT}_{4}\right)<4.78 \mathrm{pmol} / \mathrm{L}$, thyroid-stimulating hormone $>78.195 \mu \mathrm{lU} / \mathrm{mL}$, total cholesterol $>5.17 \mathrm{mmol} / \mathrm{L}$, triglycerides (TG) $>1.71 \mathrm{mmol} / \mathrm{L}$ and more than 21 days of thyroid hormone withdrawal. Multivariate analyses demonstrated that for men, $\mathrm{FT}_{4}<3.80 \mathrm{pmol} / \mathrm{L}$ and $\mathrm{TG} \geq 1.28 \mathrm{mmol} / \mathrm{L}$ were the most prominent risk factors.

Conclusions Patients with minor hepatic dysfunction and ortholiposis are more likely to recover to normal liver function. Patients with moderate hepatic dysfunction should be treated with hepatoprotective drugs. For men, $\mathrm{FT}_{4}$ and $\mathrm{TG}$ levels tended to be associated with hepatic dysfunction, and the prognosis of hepatic dysfunction was closely related to the TG level.

\section{INTRODUCTION}

Radioiodine (RAI) therapy is a very important procedure to ablate normal thyroid remnant tissues and microscopic deposits of differentiated thyroid carcinoma (DTC) after thyroidectomy. ${ }^{1}$ As reported, RAI therapy was able to reduce the number of locoregional recurrences and to increase overall survival of the American Thyroid Association (ATA) intermediate-risk and high-risk patients with DTC. ${ }^{23}$ In order to stimulate ${ }^{131}$ I uptake into the normal thyroid
Strengths and limitations of this study

The results of this study may help nuclear physicians to make clinical treatment strategies of patients with differentiated thyroid cancer.

- We selected cases with complete data to perform our retrospective analysis; however, the exclusion of a few patients who were lost to follow-up might result in potential bias.

We could not collect the result of low-density lipoprotein cholesterol measurements.

- Obesity is an important metabolic risk factor of liver and thyroid dysfunction, and it would be helpful if we could perform analysis of its influence in our study.

- For these reasons, further rigorous prospective studies are needed to confirm these preliminary findings.

remnants and metastatic tissues of thyroid carcinoma for patients with DTC who have undergone RAI therapy, an elevated thyroidstimulating hormone (thyrotropin, TSH) level is essential. ${ }^{4}$ The classic method of preparation for RAI therapy is thyroid hormone withdrawal (THW). However, the application of THW usually results in some physical or psychological side effects associated with hypothyroidism, ${ }^{5}$ such as general oedema, constipation and depression. Evidence indicates that hypothyroidism may affect liver function or structure directly. ${ }^{6}$ Therefore, the identification of factors that may cause hepatic dysfunction is rather crucial. In the present study, we collected clinical data from 996 patients with DTC to investigate the risk factors for patients with hepatic dysfunction undergoing a retrospective approach.

\section{MATERIALS AND METHODS}

\section{Participants or criteria selection}

The study included 996 patients (314 men, 682 women; age of $45.07 \pm 12.98$ years) who had undergone RAI therapy at our department from 
January 2012 to March 2018. The patients had undergone complete or partial thyroidectomy performed by various surgeons. The patients agreed to receive RAI therapy and were informed about the traditional preparation method, THW. We used hepatitis virus markers, abdominal ultrasonography, echocardiography, and autoantibody and immunoglobulin subtype determination for patients with hepatic dysfunction to exclude other apparent causes of liver damage. Other possible causes included viral hepatitis, liver cirrhosis or biliary tract disease, chronic cardiac dysfunction and autoimmune liver disease, liver steatosis, hyperlipoidemia, etc. ${ }^{7}$

\section{Patient and public involvement}

This was an uncontrolled retrospective study; patients of this study had undergone RAI therapy at our department, and we recorded and analysed the data in order to investigate the risk factors for patients with hepatic dysfunction.

\section{Data collection and grouping}

All RAI therapy regimens were conducted by the same nuclear medicine department following a standard protocol (2015 ATA Management Guidelines). Relevant data were recorded during the RAI therapy, including patient age (named $\left.\mathrm{X}_{1}\right)$, sex $\left(\mathrm{X}_{2}\right)$, the time between surgery and ${ }^{131}$ I therapy $\left(\mathrm{X}_{3}\right)$, the time of THW $\left(\mathrm{X}_{4}\right)$, the presence or absence of metastases (lymph node metastasis or lung metastasis) $\left(\mathrm{X}_{5}\right)$, the presence or absence of Hashimoto's thyroiditis $\left(\mathrm{X}_{6}\right)$, serum free triiodothyronine $\left(\mathrm{FT}_{3}\right)\left(\mathrm{X}_{7}\right)$, free thyroxine $\left(\mathrm{FT}_{4}\right)\left(\mathrm{X}_{8}\right)$, TSH $\left(\mathrm{X}_{9}\right)$, thyroglobulin $(\mathrm{Tg})\left(\mathrm{X}_{10}\right)$, antithyroglobulin antibody $(\mathrm{TgAb})$ $\left(\mathrm{X}_{11}\right)$, total cholesterol $(\mathrm{TC})\left(\mathrm{X}_{12}\right)$ and triglycerides $(\mathrm{TG})$ $\left(\mathrm{X}_{13}\right)$. Meanwhile, liver function test results including aspartate aminotransferase (AST), alanine aminotransferase (ALT), alkaline phosphatase (ALP), gammaglutamyl transferase (GGT), total-value bilirubin (TBIL) and direct bilirubin (DBIL) were also collected. Hepatic dysfunction was diagnosed in accordance with the following criteria: the upper limit of normal (ULN) $<$ ALT, AST or GGT $<3$ times ULN, the ULN $<$ ALP $<2$ times the ULN and/or TBIL and the ULN $<$ DBIL $<2.5$ times the ULN were defined as mild hepatic dysfunction; 3 times the ULN $<$ ALT or AST $<20$ times the ULN, 3 times the ULN $<$ GGT $<10$ times the ULN, 2 times the ULN $<$ ALP $<5$ times the ULN and/or 2.5 times the ULN $<$ TBIL, and DBIL $<5$ times the ULN were defined as moderate hepatic dysfunction; and ALT or AST $\geq 20$ times the ULN, GGT $\geq 10$ times the ULN, ALP $\geq 5$ times the ULN and/or TBIL and DBIL $\geq 5$ times the ULN were defined as severe hepatic dysfunction. ${ }^{7}$

\section{Parameter assessments}

Thyroid function tests were measured by chemiluminescence immunoassays (ADVIA Centaur XP, Siemens). Tg and $\mathrm{TgAb}$ were detected by the Immulite system (Immulite 2000, Siemens). Liver function indices were measured by colorimetry (Hitachi C7600, Japan). TC and TG levels were checked using an auto-analyser enzymatically
(Hitachi Model 7170 analyser; Hitachi, Tokyo, Japan). The dosage range of ${ }^{131} \mathrm{I}$ therapy was $3.7-7.4 \mathrm{GBq}$.

\section{Patient follow-up}

We measured the serum levels of thyroid parameters, serum lipids, and liver function indices of the 996 patients at 1, 2, 3, and 4 months after ${ }^{131}$ I therapy to evaluate their liver function.

\section{Statistical analysis}

A $\mathrm{X}^{2}$ test was used to analyse the differences between ratios. To identify risk factors for hepatic dysfunction, we used a bivariate logistic regression model (univariate analysis) and stepwise logistic regression (multivariate analysis) with a variable $\mathrm{p}<0.05$, and values $<0.05$ were considered statistically significant. The OR was used to evaluate the risk factor. Statistical analysis was performed using SPSS for Windows, V.20.

\section{RESULTS}

\section{Clinical features of hepatic dysfunction}

Overall, 31.6\% (315 of 996) of patients with DTC had hepatic dysfunction. Most patients with hepatic dysfunction had no obvious clinical symptoms except for abnormal liver function indices. The most common abnormality was elevated ALT and/or AST, with a prevalence of $47.5 \%$. The prevalence rates of mild, moderate, and severe hepatic dysfunction were $80.0 \%$ (252 of 315), $20.0 \%$ (63 of 315 ), and $0 \%$ (0 of 315), respectively.

\section{Risk factors for hepatic dysfunction in patients with DTC}

In this paper, a binary logistic regression model was established for relevant factors of hepatic dysfunction. Singlefactor analysis and binary multivariate logistic regression analysis were performed as well. Patient characteristics were compared using bivariate logistic univariate regression analysis between the two groups (table 1). In the metastases group, the numbers of patients with hepatic dysfunction and lymph node metastasis or lung metastasis were 508 and 21, respectively; and the numbers of patients without hepatic dysfunction were 245 (with lymph node metastasis) and 12 (with lung metastasis), respectively. The results showed that for male patients, the THW time, $\mathrm{FT}_{3}<2.01 \mathrm{pmol} / \mathrm{L}, \mathrm{FT}_{4}<4.78 \mathrm{pmol} / \mathrm{L}, \mathrm{TSH}>78.195 \mu \mathrm{IU} /$ $\mathrm{mL}, \mathrm{TC}>5.17 \mathrm{mmol} / \mathrm{L}$ and TG $>1.71 \mathrm{mmol} / \mathrm{L}$ were closely associated with hepatic dysfunction (OR: 0.324-3.171, all $\mathrm{p}<0.01)$.

Furthermore, the multivariate logistic regression analysis was applied to screen the relevant risk factors. In our study, we suggested the following assignments for independent variables: $X_{1}=1$ for age $\leq 45$ years and $X_{1}=2$ for age $>45$ years; $X_{2}=1$ for male sex and $X_{2}=2$ for female sex; $X_{3}=1$ if the time between total thyroidectomy and ${ }^{131} \mathrm{I}$ therapy was less than 3 months and $\mathrm{X}_{3}=2$ if the time between total thyroidectomy and ${ }^{131} \mathrm{I}$ therapy was more than 3 months; $\mathrm{X}_{4}=1,2$, and 3 if the THW time was shorter than 3 weeks, 3-4 weeks, and longer than 4 weeks, respectively; $\mathrm{X}_{5}=1$ 
Table 1 Bivariate logistic univariate regression of the factors for patients with DTC with hepatic dysfunction

\begin{tabular}{|c|c|c|c|c|c|c|c|}
\hline Relevant factors & & $\begin{array}{l}\text { With hepatic } \\
\text { dysfunction (n (\%)) }\end{array}$ & $\begin{array}{l}\text { Without hepatic } \\
\text { dysfunction (n (\%)) }\end{array}$ & B & OR value & $95 \% \mathrm{Cl}$ & $P$ value \\
\hline Age & $\begin{array}{l}\leq 45 \\
>45\end{array}$ & $\begin{array}{l}350(68.50) \\
331(68.25)\end{array}$ & $\begin{array}{l}161(31.50) \\
154(31.75)\end{array}$ & -1.011 & $\begin{array}{l}1 \\
1.011\end{array}$ & 0.744 to 1.321 & 0.934 \\
\hline $\begin{array}{l}\text { Time between thyroidectomy } \\
\text { and }{ }^{131} \text { I therapy }\end{array}$ & $\begin{array}{l}\leq 3 \text { months } \\
>3 \text { months }\end{array}$ & $\begin{array}{l}560(68.20) \\
121(69.14)\end{array}$ & $\begin{array}{l}261(31.80) \\
54(30.86)\end{array}$ & 0.043 & $\begin{array}{l}1 \\
1.044\end{array}$ & 0.734 to 1.486 & 0.810 \\
\hline Metastases & $\begin{array}{l}\text { Negative } \\
\text { Positive }\end{array}$ & $\begin{array}{l}152(72.38) \\
529(67.30)\end{array}$ & $\begin{array}{l}58(27.62) \\
257(32.70)\end{array}$ & -0.242 & $\begin{array}{l}1 \\
0.785\end{array}$ & 0.561 to 1.100 & 0.160 \\
\hline Hashimoto's thyroiditis & $\begin{array}{l}\text { Negative } \\
\text { Positive }\end{array}$ & $\begin{array}{l}595(67.85) \\
86(72.27)\end{array}$ & $\begin{array}{l}282(32.15) \\
33(27.73)\end{array}$ & -0.211 & $\begin{array}{l}1 \\
0.810\end{array}$ & 0.529 to 1.239 & 0.331 \\
\hline $\mathrm{FT}_{3}$ & $\begin{array}{l}<2.01^{*} \\
\geq 2.01\end{array}$ & $\begin{array}{l}316(63.71) \\
365(73.00)\end{array}$ & $\begin{array}{l}180(36.29) \\
135(27.00)\end{array}$ & 0.432 & $\begin{array}{l}1 \\
1.540\end{array}$ & 1.177 to 2.016 & 0.002 \\
\hline TSH & $\begin{array}{l}<78.195^{*} \\
\geq 78.195\end{array}$ & $\begin{array}{l}365(73.29) \\
316(63.45)\end{array}$ & $\begin{array}{l}133(26.71) \\
182(36.55)\end{array}$ & -0.458 & $\begin{array}{l}1 \\
0.633\end{array}$ & 0.483 to 0.828 & 0.001 \\
\hline $\mathrm{Tg}$ & $\begin{array}{l}<2.635^{\star} \\
\geq 2.635\end{array}$ & $\begin{array}{l}346(69.48) \\
335(67.27)\end{array}$ & $\begin{array}{l}152(30.52) \\
163(32.73)\end{array}$ & -0.185 & $\begin{array}{l}1 \\
0.831\end{array}$ & 0.609 to 1.134 & 0.244 \\
\hline $\operatorname{TgAb}$ & $\begin{array}{l}\leq 40 \dagger \\
>40\end{array}$ & $\begin{array}{l}527(66.96) \\
154(73.68)\end{array}$ & $\begin{array}{l}260(33.04) \\
55(26.32)\end{array}$ & 0.381 & $\begin{array}{l}1 \\
1.374\end{array}$ & 0.979 to 1.930 & 0.067 \\
\hline TC & $\begin{array}{l}\leq 5.17 \dagger \\
>5.17\end{array}$ & $\begin{array}{l}129(75.44) \\
552(66.90)\end{array}$ & $\begin{array}{l}42(24.56) \\
273(33.10)\end{array}$ & 0.758 & $\begin{array}{l}1 \\
2.135\end{array}$ & 1.615 to 2.822 & 0.000 \\
\hline TG & $\begin{array}{l}\leq 1.71 \dagger \\
>1.71\end{array}$ & $\begin{array}{l}336(77.42) \\
344(61.54)\end{array}$ & $\begin{array}{l}98(22.58) \\
215(38.46)\end{array}$ & -0.418 & $\begin{array}{l}1 \\
0.658\end{array}$ & 0.451 to 0.960 & 0.03 \\
\hline
\end{tabular}

*Median.

†Upper limit of the normal value.

DTC, differentiated thyroid cancer; $\mathrm{FT}_{3}$, free triiodothyronine; $\mathrm{FT}_{4}$, free thyroxine; $\mathrm{TC}$, total cholesterol; Tg, thyroglobulin; $\mathrm{TG}$, triglycerides; TgAb, antithyroglobulin antibody; TSH, thyroid-stimulating hormone.

for the presence of metastases and $\mathrm{X}_{5}=2$ for the absence of metastases; $\mathrm{X}_{6}=1$ for the presence of Hashimoto's thyroiditis and $\mathrm{X}_{6}=2$ for the absence of Hashimoto's thyroiditis; $\mathrm{X}_{7}=1,2,3$, and 4 for $\mathrm{FT}_{3}$ levels lower than $1.60 \mathrm{pmol} / \mathrm{L}, 1.60-2.01 \mathrm{pmol} / \mathrm{L}, 2.01-2.37 \mathrm{pmol} / \mathrm{L}$, and higher than $2.37 \mathrm{pmol} / \mathrm{L}$, respectively; $\mathrm{X}_{8}=1,2,3$, and 4 for $\mathrm{FT}_{4}$ levels lower than $3.80 \mathrm{pmol} / \mathrm{L}, 3.80-4.78 \mathrm{pmol} / \mathrm{L}$, 4.78-5.79 pmol/L, and higher than $5.79 \mathrm{pmol} / \mathrm{L}$, respectively; $\mathrm{X}_{9}=1,2,3$, and 4 for TSH levels lower than 57.01 $\mu \mathrm{IU} / \mathrm{mL}, 57.01-78.20 \mu \mathrm{IU} / \mathrm{mL}, 78.20-101.84 \mu \mathrm{IU} / \mathrm{mL}$, and higher than $101.84 \mu \mathrm{IU} / \mathrm{mL}$, respectively; $\mathrm{X}_{10}=1$, 2, 3, and 4 for $\mathrm{Tg}$ levels lower than $0.50 \mathrm{ng} / \mathrm{mL}, 0.50-$ $2.64 \mathrm{ng} / \mathrm{mL}, 2.64-9.18 \mathrm{ng} / \mathrm{mL}$, and higher than $9.18 \mathrm{ng} /$ $\mathrm{mL}$, respectively; $\mathrm{X}_{11}=1$ for TgAb levels lower than $40 \mathrm{IU} /$ $\mathrm{mL}$ and $\mathrm{X}_{11}=2$ for $\mathrm{TgAb}$ levels higher than $40 \mathrm{IU} / \mathrm{mL}$; $\mathrm{X}_{12}=1,2,3$, and 4 for TC levels lower than $5.46 \mathrm{mmol} / \mathrm{L}$, $5.46-6.27 \mathrm{mmol} / \mathrm{L}, 6.27-7.22 \mathrm{mmol} / \mathrm{L}$, and higher than $6.27 \mathrm{mmol} / \mathrm{L}$, respectively; and $\mathrm{X}_{13}=1,2,3$, and 4 for TG levels lower than $1.28 \mathrm{mmol} / \mathrm{L}, 1.28-1.85 \mathrm{mmol} / \mathrm{L}, 1.85-$ $2.76 \mathrm{mmol} / \mathrm{L}$, and higher than $2.76 \mathrm{mmol} / \mathrm{L}$, respectively. Resultant variable: $\mathrm{Y}=1$ for patients with hepatic dysfunction, and $\mathrm{Y}=0$ for patients without hepatic dysfunction. Forward stepwise regression analysis rejecting trends ultimately revealed that male sex, $\mathrm{FT}_{4}<3.80 \mathrm{pmol} / \mathrm{L}$ and TG $\geq 1.28 \mathrm{mmol} / \mathrm{L}$ were independent risk factors to predict hepatic dysfunction in patients with DTC (table 2).

\section{Outcomes of hepatic dysfunction after ${ }^{131} I$ therapy}

The outcomes of hepatic dysfunction of varying degrees after ${ }^{131}$ I therapy are displayed in table 3 . The remission rate of patients at 1 month after ${ }^{131}$ I therapy was $86.34 \%$ (272 of $315)$. Liver function test results revealed that $90.07 \%(227$ of 252) of patients with mild hepatic dysfunction returned to normal 1 month after ${ }^{131}$ I therapy. Moreover, the remission rate among patients with moderate and severe hepatic dysfunction was $71.43 \%$ (45 of 63). Additionally, the remission rate of mild hepatic dysfunction was higher than that of moderate dysfunction $(\mathrm{p}<0.001)$.

The remission of hepatic dysfunction at 1 month after ${ }^{131}$ I therapy is shown in table 4 . The liver function tests of 252 patients with mild hepatic dysfunction were evaluated at 1 month after ${ }^{131}$ I therapy. Results showed that the liver function of $94.34 \%$ (50 of 53) of patients who were given hepatoprotective treatment (oral bicyclol tablets, bicyclol $25 \mathrm{mg} /$ tablet, Beijing Union Pharmaceutical Factory, Beijing, China, at a total daily dose of $75 \mathrm{mg}$ ( $25 \mathrm{mg}$ three times per day), the treated group) returned to normal after 1 month of ${ }^{131} \mathrm{I}$ therapy. Moreover, the remission 
Table 2 Bivariate logistic multivariate regression analysis of the factors for patients with DTC with hepatic dysfunction

\begin{tabular}{|c|c|c|c|c|c|c|c|}
\hline Causal variable & B & SE & Wald & df & $P$ value & $\operatorname{Exp}(B)$ & $95 \% \mathrm{Cl}$ \\
\hline $\mathrm{X}_{2}$ & -0.933 & 0.156 & 35.703 & 1 & 0.000 & 0.393 & 0.290 to 0.534 \\
\hline $\mathrm{X}_{8}\left(\mathrm{FT}_{4}\right)$ & & & 62.291 & 3 & 0.000 & & \\
\hline $\mathrm{X}_{8}(3)$ & -0.853 & 0.200 & 18.146 & 1 & 0.000 & 0.426 & 0.288 to 0.631 \\
\hline$X_{8}(4)$ & -1.789 & 0.239 & 55.817 & 1 & 0.000 & 0.167 & 0.105 to 0.267 \\
\hline$X_{13}(2)$ & 0.325 & 0.225 & 2.072 & 1 & 0.150 & 1.383 & 0.889 to 2.152 \\
\hline $\mathrm{X}_{13}(3)$ & 0.643 & 0.223 & 8.313 & 1 & 0.004 & 1.901 & 1.228 to 2.943 \\
\hline$X_{13}(4)$ & 0.787 & 0.219 & 12.784 & 1 & 0.000 & 2.197 & 1.429 to 3.376 \\
\hline Constant & -0.188 & 0.270 & 0.484 & 1 & 0.487 & 0.829 & \\
\hline
\end{tabular}

DTC, differentiated thyroid carcinoma; $\mathrm{FT}_{4}$, free thyroxine.

rate among patients in the untreated group was found to be $88.94 \%$ (177 of 199$)$. However, no remarkable difference in the remission rate was observed between the two groups $(p=0.184)$.

Other 63 patients with moderate hepatic dysfunction were treated with hepatoprotective therapy (oral bicyclol tablets, at a total daily dose of $150 \mathrm{mg}$ ( $50 \mathrm{mg}$ three times per day)), and the remission rates among patients at 1 month, 2 months, and 3 months after ${ }^{131}$ I therapy were $55.56 \%$ (35 of 63 ), $36.5 \%$ (23 of 63 ), and $7.94 \%$ (5 of $63)$, respectively. The average time for liver function to return to normal level in patients with moderate hepatic dysfunction was 1.8 months.

\section{The correlation between serum TG and the remission rate of} hepatic dysfunction in patients with DTC

The numbers of patients with hyperlipidaemia, hyperlipidaemia with hepatic dysfunction, and dyslipidaemia (hypercholesterolaemia+hypertriglyceridaemia) were 564,278 and 244, respectively. A total of 559 patients (218 men, 341 women) had elevated serum TG before ${ }^{131}$ I therapy, including 189 patients with hepatic dysfunction (76 men, 113 women). All patients were divided into two subgroups based on their serum TG levels 1 month after

${ }^{131}$ I therapy: subgroup 1 includes subjects with a normal TG level (141 patients) and subgroup 2 includes subjects with elevated TG (48 patients, 21 women, 27 men). In subgroup 2, 15 men and 10 women were treated with statins or fenofibrate for lipid-lowering therapy. The

Table 3 Outcomes of hepatic dysfunction of varying degrees after 1 month of ${ }^{131}$ I therapy

\begin{tabular}{llll}
\hline & & \multicolumn{2}{l}{ Outcomes (n (\%)) } \\
\cline { 3 - 4 } Degree & $\mathbf{n}$ & Remission & Non-remission \\
\hline Mild & 252 & $227(90.07)$ & $25(9.93)$ \\
Moderate & 63 & $45(71.43)$ & $18(28.57)$ \\
$\chi^{2}$ & & 14.873 & \\
$P$ value & & 0.000 & \\
\hline
\end{tabular}

percentage of patients with liver function who returned to normal was $92.90 \%$ (131 of 141) in subgroup 1. Moreover, the remission rate of the patients in subgroup 2 was $75.00 \%$ (36 of 48) $\left(\chi^{2}=5.382, p=0.02\right)$. In subgroup 2 , the remission rates of the patients with lipid-lowering therapy were $84.00 \%$ (21 of 25 ) and $65.21 \%$ (15 of 23 ).

\section{DISCUSSION}

A complex relationship between the thyroid gland and the liver exists in both healthy and disease states. Malik's ${ }^{8}$ research showed that thyroid dysfunction may affect liver function. ${ }^{9}$ It is suggested that a relationship may exist between non-alcoholic fatty liver disease (NAFLD) and thyroid dysfunction. ${ }^{10}$ Several studies conducted in some countries worldwide showed that the relationship between levels of thyroid hormones and the incidence of NAFLD was inverse. ${ }^{11}$ In clinical practice, we have found that hepatic dysfunction in patients with DTC is common, and most of these patients have no obvious symptoms. The mechanism may be related to the following factors ${ }^{12}$ : (1) hypothyroidism may have features similar to those of liver diseases (pseudo-liver disease, such as myalgias, fatigue and muscle cramps in the presence of elevated AST from myopathy, coma); (2) hypothyroidism may interact with liver structure or function directly, for example, bilirubin excretion is reduced in experimental hypothyroidism with the decrease of the activity of bilirubin UDP-glucuronyltransferase; (3) hypothyroidism is

Table 4 Remission of hepatic dysfunction among patients given different treatments at 1 month after ${ }^{131}$ I therapy

\begin{tabular}{lrlc} 
& & \multicolumn{2}{l}{ Outcomes (n (\%)) } \\
\cline { 3 - 4 } Group & $\mathbf{n}$ & Remission & Non-remission \\
\hline Treatment & 53 & $50(94.34)$ & $3(5.66)$ \\
No treatment & 199 & $177(88.94)$ & $22(11.06)$ \\
$\chi^{2}$ & & 1.765 & \\
P value & & 0.184 & \\
\hline
\end{tabular}


related to cholestatic jaundice due to decreased bilirubin and bile excretion ${ }^{13}$; and (4) severe hypothyroidism is known to cause increased permeability of the vascular endothelium ${ }^{14}$.

Our study demonstrated that $31.6 \%$ of patients with DTC suffered from different degrees of hepatic dysfunction. All of these patients had mild or moderate liver injury. Additionally, an increase in ALT or AST was the most common abnormal indicator, and the prevalence was $47.5 \%$. The findings are different from previous research data from Gokmen's group whose research showed that hypertriglyceridaemia and a higher $\mathrm{FT}_{3} / \mathrm{FT}_{4}$ ratio are independent risk factors for NAFLD; however, hypothyroidism is not related to the condition directly. ${ }^{15}$ However, their research subjects were patients with hypothyroidism, where hypothyroidism was defined only by a TSH level $\geq 4.1 \mathrm{mIU} / \mathrm{L}$, and $\mathrm{FT}_{3}$ and $\mathrm{FT}_{4}$ levels were not included. The $\mathrm{FT}_{3}$ and $\mathrm{FT}_{4}$ levels of some patients were normal.

To explore the risk factors of hepatic dysfunction for patients with DTC, we analysed 13 related factors, and found that male sex, a THW time greater than 21 days, $\mathrm{FT}_{3}$ $<2.01 \mathrm{pmol} / \mathrm{L}, \mathrm{FT}_{4}<4.78 \mathrm{pmol} / \mathrm{L}, \mathrm{TSH}>78.195 \mu \mathrm{IU} / \mathrm{mL}$, TC $>5.17 \mathrm{mmol} / \mathrm{L}$ and TG $>1.71 \mathrm{mmol} / \mathrm{L}$ were responsible risk factors for hepatic dysfunction in the univariate analysis (all $\mathrm{p}<0.01$ ). Additionally, we found that male sex, $\mathrm{FT}_{4}<3.80 \mathrm{pmol} / \mathrm{L}$ and $\mathrm{TG} \geq 1.28 \mathrm{mmol} / \mathrm{L}$ were closely associated with hepatic dysfunction in patients with DTC in the multivariate logistic regression analysis $(p<0.01)$. No other studies related to our study on the risk factors of hepatic dysfunction for patients with DTC were found.

In this study, we found that the remission rate of patients with mild hepatic dysfunction was significantly higher than that of patients with moderate hepatic dysfunction at 1 month after ${ }^{131}$ I therapy. Additionally, no significant differences can be found on the remission rate among patients with mild hepatic dysfunction between the treated and untreated groups. It was also found that the $\mathrm{FT}_{4}$ level is highly associated with hepatic dysfunction, with more severe hypothyroidism corresponding to a greater impact on liver function. Patients with mild hepatic dysfunction may not be treated with hepatoprotective drugs because the remission rate of hepatic dysfunction at 1 month after ${ }^{131}$ I therapy was not significantly different between the treated and untreated groups. Recent studies revealed that with no liver damage, hepatic dysfunction associated with hypothyroidism can be reversed over several weeks with thyroxine replacement. ${ }^{16}$

Additionally, liver is the vital organ for cholesterol metabolism and thyroid hormones, which plays an important role in hepatic lipid metabolism. ${ }^{17}$ Thyroid hormones can increase the activity of lipid-lowering liver enzymes which can cause a reduction in low-density lipoprotein levels. ${ }^{18}$ As reported, serum lipids also play an important role in liver function, ${ }^{19}$ which coincided with the results of our study. In our study, hepatic function indices returned to normal at 1 month after ${ }^{131}$ I therapy in $86.34 \%$ of the patients, the remission rate in patients with normal TG levels was significantly higher than that in the elevated TG group. In addition, the time until liver dysfunction returned to normal level in the patients suffering from hyperlipidaemia and hepatic dysfunction was longer than that of the patients suffering from only hepatic dysfunction. In other words, lipid-lowering therapy (statins or fenofibrate) was very important for patients with hepatic dysfunction.

Obesity is an important metabolic risk factor of liver and thyroid dysfunction, and it would be helpful if we could provide analysis of its influence in our study. However, due to the limitations, this part of analysis was not included in the current paper. For this reason, further rigorous prospective studies are needed to confirm these preliminary findings.

\section{CONCLUSIONS}

Hepatic dysfunction is more likely to occur in male patients and patients with a THW time greater than 21 days, $\mathrm{FT}_{3}<2.01 \mathrm{pmol} / \mathrm{L}, \mathrm{FT}_{4}<4.78 \mathrm{pmol} / \mathrm{L}, \mathrm{TSH}>78.195$ $\mu \mathrm{IU} / \mathrm{mL}, \mathrm{TC}>5.17 \mathrm{mmol} / \mathrm{L}$ and TG $>1.71 \mathrm{mmol} / \mathrm{L}$. Additionally, lipid-lowering therapy is particularly important for patients with DTC with hepatic dysfunction before ${ }^{131}$ I therapy. For patients with DTC with hepatic dysfunction combined with dyslipidaemia, lipid-lowering therapy is recommended, which is expected to shorten the remission time of hepatic dysfunction.

\section{Contribution to the field statement}

An elevated TSH level is essential to stimulate ${ }^{131}$ I uptake when a patient with DTC undergoes RAI therapy. A number of patients suffer from general oedema, constipation and so on, before RAI therapy with THW. Evidence reveals that hypothyroidism may have a direct effect on liver structure or function. We retrospectively collected clinical data from 996 patients with DTC to investigate the relevant risk factors of hepatic dysfunction in these patients. Patients with mild hepatic dysfunction and ortholiposis were found to have a higher likelihood of recovering to normal liver function. For men, $\mathrm{FT}_{4}$ and TG levels were more closely related to hepatic dysfunction, and the prognosis of hepatic dysfunction was closely associated with the TG level.

\section{Acknowledgements Thanks all the patients who participated in this study.}

Contributors YJ and RW contributed to the conception and design of the study. YJ, WZ, JT and CW assisted with data acquisition. YJ, ZM and RW conducted the statistical analyses and drafted the manuscript. JT and ZM critically revised the manuscript. All authors read and approved the final manuscript and agree to be accountable for all aspects of the research in ensuring that the accuracy or integrity of any part of the work is appropriately investigated and resolved. RW is the author responsible for the overall content as the guarantor.

Funding This study was sponsored by the Natural Science Foundation of Tianjin City (grant no. 20JCQNJC01610).

Competing interests None declared.

Patient and public involvement Patients and/or the public were not involved in the design, or conduct, or reporting, or dissemination plans of this research.

Patient consent for publication Obtained. 
Ethics approval This study is a retrospective clinical study summarising and analysing a large amount of clinical data. The ethics committee of Tianjin Medical University General Hospital waived the need to obtain written informed consent from all patients. All clinical data used in this study were analysed anonymously.

Provenance and peer review Not commissioned; externally peer reviewed.

Data availability statement All data relevant to the study are included in the article or uploaded as supplemental information. Not applicable.

Open access This is an open access article distributed in accordance with the Creative Commons Attribution Non Commercial (CC BY-NC 4.0) license, which permits others to distribute, remix, adapt, build upon this work non-commercially, and license their derivative works on different terms, provided the original work is properly cited, appropriate credit is given, any changes made indicated, and the use is non-commercial. See: http://creativecommons.org/licenses/by-nc/4.0/.

ORCID iD

Yanhui Ji http://orcid.org/0000-0003-1697-4697

\section{REFERENCES}

1 Robbins RJ, Larson SM, Sinha N, et al. A retrospective review of the effectiveness of recombinant human TSH as a preparation for radioiodine thyroid remnant ablation. $J$ Nucl Med 2002;43:1482-8.

2 Greenspan BS. Radioiodine treatment of well-differentiated thyroid cancer: balancing risks and benefits. J Clin Oncol 2018;36:1785-7.

3 Choudhury PS, Gupta M. Differentiated thyroid cancer theranostics: radioiodine and beyond. Br J Radiol 2018;91:20180136.

4 Mazzaferri EL, Kloos RT. Clinical review 128: current approaches to primary therapy for papillary and follicular thyroid cancer. J Clin Endocrinol Metab 2001;86:1447-63.

5 Han Y-H, Lim ST, Yun K-N, et al. Comparison of the influence on the liver function between thyroid hormone withdrawal and rh-TSH before high-dose radioiodine therapy in patients with well-differentiated thyroid cancer. Nucl Med Mol Imaging 2012;46:89-94.
6 Haugen BR, Alexander EK, Bible KC. The American thyroid association guidelines Task force on thyroid nodules and differentiated thyroid cancer. Thyroid 2016;26:1-133.

7 Tuttle RM, Brokhin M, Omry G, et al. Recombinant human TSHassisted radioactive iodine remnant ablation achieves short-term clinical recurrence rates similar to those of traditional thyroid hormone withdrawal. J Nucl Med 2008;49:764-70.

8 Malik R, Hodgson $\mathrm{H}$. The relationship between the thyroid gland and the liver. QJM 2002:95:559-69.

9 Feisa SV, Chopei IV. Subclinical hypothyroidism in patients with non-alcoholic fatty liver disease at the background of carbohydrate metabolism disorders. Wiad Lek 2018;7129729151:261-4.

10 Wang R, Tan J, Zhang G, et al. Risk factors of hepatic dysfunction in patients with Graves' hyperthyroidism and the efficacy of 131iodine treatment. Medicine 2017;96:e6035.

11 Thobe N, Pilger P, Jones MP. Primary hypothyroidism masquerading as hepatic encephalopathy: case report and review of the literature. Postgrad Med J 2000;76:424-6.

12 Chung GE, Kim D, Kim W, et al. Non-Alcoholic fatty liver disease across the spectrum of hypothyroidism. $J$ Hepatol 2012;57:150-6.

13 Sinha RA, Singh BK, Yen PM. Direct effects of thyroid hormones on hepatic lipid metabolism. Nat Rev Endocrinol 2018;14:259-69.

14 Kinney EL, Wright RJ, Caldwell JW. Value of clinical features for distinguishing myxedema ascites from other forms of ascites. Comput Biol Med 1989;19:55-9.

15 Gökmen FY, Ahbab S, Ataoğlu HE, et al. FT3/FT4 ratio predicts non-alcoholic fatty liver disease independent of metabolic parameters in patients with euthyroidism and hypothyroidism. Clinics 2016;71:221-5

16 Baker A, Kaplan M, Wolfe $\mathrm{H}$. Central congestive fibrosis of the liver in myxedema ascites. Ann Intern Med 1972;77:927-9.

17 Inkinen J, Sand J, Nordback I. Association between common bile duct stones and treated hypothyroidism. Hepatogastroenterology 2000;47:919-21.

18 Khemichian S, Fong T-L. Hepatic dysfunction in hyperthyroidism. Gastroenterol Hepatol 2011;7:337-9.

19 Fabbrini E, Magkos F, Patterson BW, et al. Subclinical hypothyroidism and hyperthyroidism have opposite effects on hepatic very-low-density lipoprotein-triglyceride kinetics. J Clin Endocrinol Metab 2012;97:E414-8. 